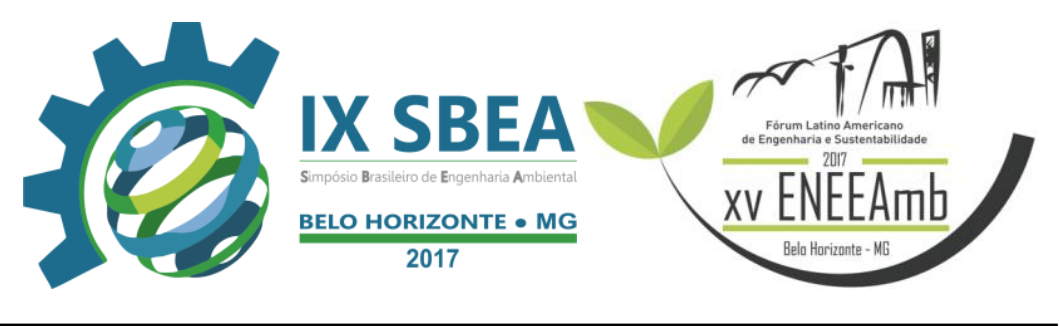

ÁREA TEMÁTICA: GESTÃO AMBIENTAL E POLÍTICAS PÚBLICAS

\title{
CONSELHO MUNICIPAL DE MEIO AMBIENTE DE VITÓRIA DA CONQUISTA E AS PRINCIPAIS ATIVIDADES REALIZADAS - COMMAM
}

Aline Rocha Brito - alinerochaambiental@gmail.com Instituto Federal da Bahia

Letícia de Jesus Castro Morais dos Santos - 1_lele@ hotmail.com Instituto Federal da Bahia

Claunita Novais Alves - caualves_16@ hotmail.com Instituto Federal da Bahia

Deise Fracarolli Spinola - deise.fracspi@ yahoo.com.br Instituto Federal da Bahia

Michelle Viana Campos - michelleroc@ hotmail.com Instituto Federal da Bahia Acimarney Correia Silva Freitas - acimarney@gmail.com Instituto Federal da Bahia 


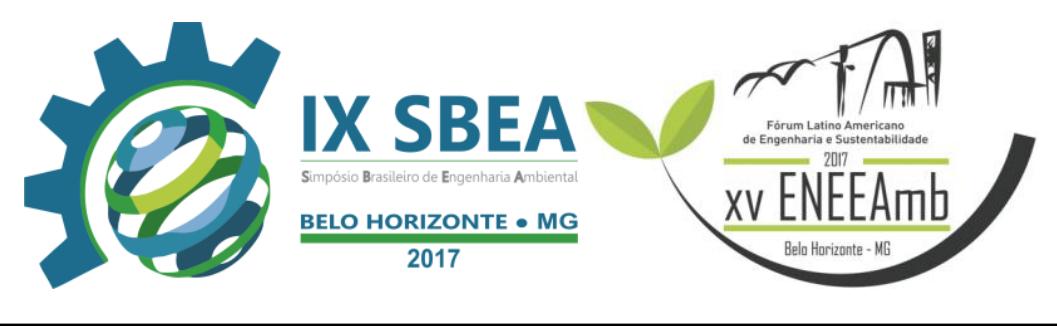

\section{RESUMO}

Este trabalho efetua uma análise do Conselho Municipal de Meio Ambiente de Vitória da Conquista, conhecido como COMMAM, através de pesquisas e informações obtidas tanto na Secretária Municipal de meio Ambiente da cidade quanto com representantes do conselho. Com a coleta desses dados foi possível descrever o que é o COMMAM, as suas funções, e quem são os representantes que compõem esse órgão. Também foi obtido conhecimento das principais atividades realizadas pelo conselho em 2012. Foi possível perceber com esse estudo se o conselho está conseguindo cumprir seus objetivos e se os projetos idealizados nas reuniões estão saindo do papel. Apesar da importância do Conselho foi possível observar desvalorização por parte da população.

Palavras-chave: COMMAM, pesquisas, preservação ambiental.

\section{INTRODUÇÃO/OBJETIVO}

Os conselhos municipais de Meio Ambiente foram criados para que a população e o poder público possam participar da gestão ambiental em suas cidades, em Vitória Da Conquista este conselho surgiu através da Lei $\mathrm{n}^{\circ}$ 1.085/2001, com objetivo de acompanhar o desenvolvimento sustentável e as políticas ambientais do município. Os conselhos têm como função opinar e assessorar o poder executivo municipal (a Prefeitura, as secretarias e o Órgão ambiental municipal). As reuniões realizadas pelo conselho tomam decisões e possuem caráter deliberativo, consultivo e normativo. Os conselhos possuem fundamentação jurídica no artigo 20 da resolução no ${ }^{\circ}$ 237/97 do CONAMA que diz que para os entes federados exercerem licenciamentos eles devem implementar os Conselhos de Meio Ambiente "com caráter deliberativo e participação social e, ainda, possuir em seus quadros ou a sua disposição profissionais legalmente habilitados". Em Vitória da Conquista o Conselho Municipal de Meio Ambiente é conhecido como COMMAM. E com o surgimento da lei n0 547/1990 surge o Conselho de Defesa do Meio Ambiente (CODEMA), este órgão tem como objetivo defender o meio ambiente, da poluição, degradação ambiental como atividades extrativas vegetais e minerais, também a preocupação do uso do solo e os recursos hídricos da cidade, preservando a natureza. Através das preocupações socioambientais e a preservação do meio ambiente, a secretária de meio ambiente da cidade, junto como esses órgãos 


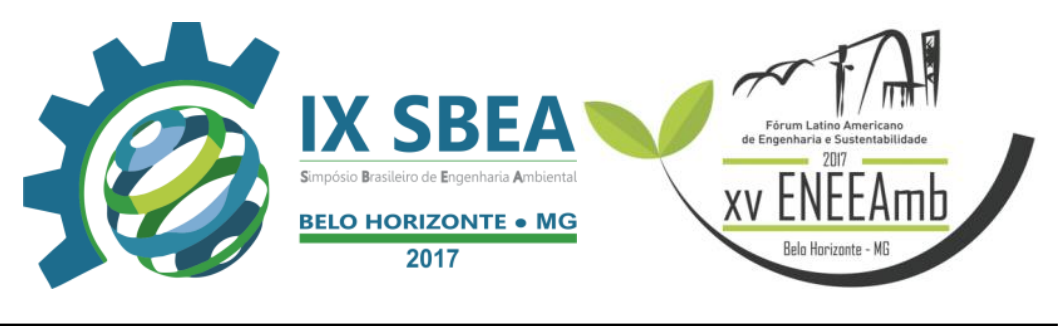

promovem projetos de sustentabilidade na cidade, promovendo a educação ambiental, a conscientização da população e além de propor a criação de normas legais, bem como adequação e regulamentação de leis, tanto nos aspectos federativos, municipais e estaduais. Os projetos desenvolvidos para a conservação do meio ambiente são programas voltados para a conscientização da sociedade, entre eles estão restauração das praças, cidade verde, florestas urbanas, intervenção no uso do agrotóxico em Lagoas Das Flores, brincando na lagoa, semana do meio ambiente e entre outros.

O objetivo dessa pesquisa tem como intuito mostrar a importância desses órgãos, junto com secretária de meio ambiente, e os projetos que são desenvolvidos e como são executados dentro da cidade para o melhoramento do município, contando com a preservação do meio ambiente e proporcionando o desenvolvimento sustentável.

\section{METODOLOGIA}

Este artigo foi construído a partir do levantamento de dados encontrados na literatura já existente. Foram realizadas pesquisas bibliográficas em livros e por meio de artigos e informações existentes na Web e em sites especializados.

\section{RESULTADOS E DISCUSSÃO}

O conselho municipal de meio ambiente é um órgão criado para os fins de preocupação com a qualidade ambiental, e vem crescendo de acordo com a necessidade da população e para o uso consciente dos recursos naturais, bem como, para a recuperação do meio ambiente. A preocupação ambiental vem crescendo rapidamente nos municípios brasileiros, onde cria-se mecanismos para aumentar a consciência da população e para promover o bem-estar populacional, viabilizando o desenvolvimento de projetos para o melhoramento do município.

De acordo com a Lei Municipal $\mathrm{n}^{\circ} 1.085$, de 28 de dezembro de 2001. Conhecido como COMMAM, esse é um órgão de natureza permanente e de caráter consultivo, deliberativo e normativo do Sistema Municipal do Meio Ambiente, o qual passará a ser regido pelo Código de Meio Ambiente de Vitória da Conquista (LEI N. ${ }^{\circ}$ 1.410/2007). 


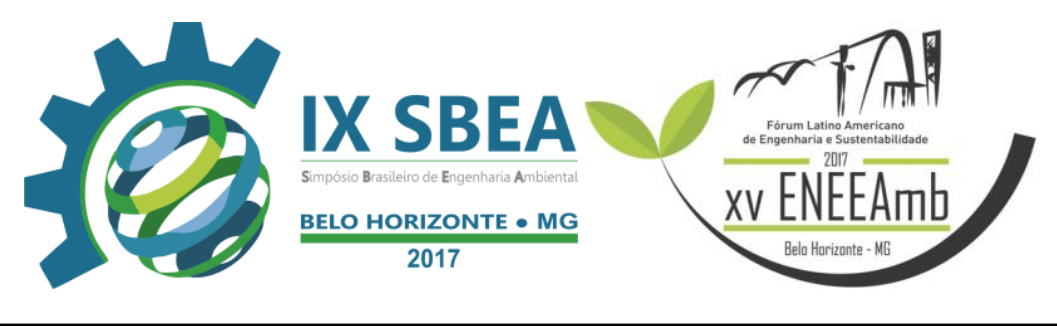

A política do meio ambiente de Vitoria da Conquista é tratada pelo COMMAM, onde serão estabelecidas normas e diretrizes, para a proteção ambiental, proporcionando estratégias para o desenvolvimento sustentável, analisar projetos de empreendimentos que causa algum impacto ambiental, assim fazendo se o uso do licenciamento ambiental, onde haverá estudos de impactos prévios. Deverá também dar o acesso a população sobre as questões ambientais, estimular que a mesma participe dos projetos realizados como preservação do meio ambiente.

Este órgão tem por objetivo aprovar planos de áreas degradadas, proteger a fauna e a flora que esteja em extinção, mananciais, patrimônio histórico. Orientar a educação ambiental no município, visando à conscientização da população promovendo palestras, estudos e eventos. Manter o intercâmbio entre os órgãos federais e estaduais, e entre outras atribuições existentes. O COMMAM compõe-se de 24 membros presentes, 12 são representantes de órgão Governamentais e os outros 12 são representantes de entidades e órgão relacionados à sociedade. Dos representantes dos órgãos governamentais tem-se o secretário de meio ambiente, que atualmente é Hudson Castro, e representante das secretarias de saúde, transporte infraestrutura urbana, Educação, Serviços Públicos, Agricultura e Desenvolvimento Rural, estadual do meio ambiente e recursos hídricos (SEMA), também representantes da agencia de desenvolvimento do órgão ambiental federal, universidades públicas no Município; do Centro Federal de Educação Tecnológica e um representante da Empresa Concessionária dos Serviços de Águas e Saneamento do Município (EMBASA). Os outros 12 representantes da sociedade civil são da Associação das Indústrias de Vitória da Conquista, da Ordem dos Advogados do Brasil - OAB-Ba, de Entidades ou Associações Civis (cujos objetivos estatutários sejam a proteção, prevenção e conservação do meio ambiente), das Associações de Moradores da cidade, do Conselho Regional de Engenharia e Arquitetura, de Associações de Reflorestamento, de movimentos populares organizados de assentamentos, dos Sindicatos dos Trabalhadores Rurais, do Patronal Rural, dos Trabalhadores Urbanos. Um representante de universidades particulares no Município.

Foram obtidas Informações pela Secretária de Meio Ambiente de Vitória da Conquista sobre as atividades realizadas em 2012. Poucos projetos foram feitos nesse período por se tratar de ano eleitoral. E alguns projetos que começaram ano passado 


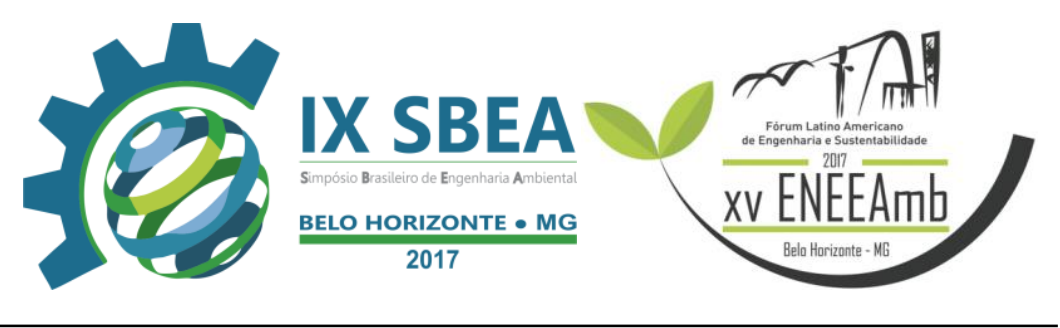

ainda estão em execução, como exemplo da Cidade verde, restauração das praças, projetos de diagnóstico e monitoramento socioambiental do Parque Lagoa das Bateias, Projeto Floresta Urbana, Adote uma praça. Além de programações realizadas, principalmente na semana de Meio Ambiente, como a Eletro-troca. O programa Restauração de praças realiza ações como melhorar a estrutura física, deixa-las mais bonitas, restaurar e instalar iluminação nas mesmas, tornando as praças locais de lazer e realização de atividades físicas. Com isso a população se sente motivada a conservar e preservar essas áreas. Em 2012 esse projeto foi implantado em algumas praças da cidade, na Praça Gerson Sales, no Alto Maron, na Praça Orlando Leite, mais conhecida como pracinha do Gil, na Praça Vitor Brito e por último, na Praça do Cajá. Mais, porém sofre com ação do vandalismo por conta da falta de educação de algumas pessoas, simplesmente muitos arrancam, plantas e árvores plantadas ou até mesmo quebram nas localidades das praças, ainda falta uma educação ambiental que envolva a população a preservação, e que o meio ambiente é meio em que vivemos, um local onde podemos desfrutar de uma cidade limpa e arborizada onde uma praça se torne um local de lazer e prazer.

Também estar em execução o projeto de diagnóstico e monitoramento socioambiental do parque lagoa das bateias, realizar o diagnóstico e monitoramento socioeconômico e ambiental, incluindo os bairros adjacentes, visando avaliar as principais causas de degradação ambiental do local e propor medidas mitigadoras dos impactos ambientais negativos. O projeto adote uma praça o objetivo é de assegurar a preservação do espaço público para lazer a partir do apoio de entidades e dos empresários locais, as ações do programa trazem resultados favoráveis, como a manutenção periódica, modernização e até reformas do local. As intervenções acontecem com acompanhamento com o apoio da secretaria de meio ambiente. De acordo com a lei 1649/2009 entidades sociais ou empresas privadas de Vitória da Conquista podem contribuir com a preservação e o embelezamento do local, como é o caso da antiga Praça do Cajá, que foi adotada por uma empresa de limpeza e seu nome atualmente é Praça José Pinho Marinho de Andrade, o Mira Flores Monumento adotou duas praças. 


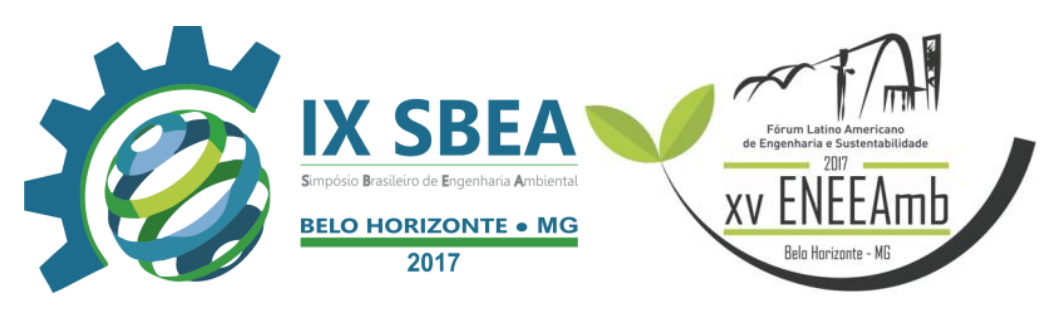

O projeto eletro-troca organizado pela a secretaria de meio ambiente, e com a parceria da Cooperativa de Catadores Recicla Conquista, visa troca de eletrônicos como aparelhos de som, computadores, baterias e entre vários outros, estes eletrônicos serão trocados por uma muda de uma planta, é organizado em praças de grandes movimentações, onde as pessoas são os principais alvos para a conscientização, ali a população poderão fazer os descartes de aparelhos, que se forem jogados no lixo de qualquer maneira irá poluir o meio ambiente. $\mathrm{O}$ dia da eletro-troca ficou conhecido como o dia ' $\mathrm{D}$ ' acontece anualmente, as atividades são socioeducativas que se interage com a programação da semana do meio ambiente.

Mais com toda a estrutura do projeto ainda encontramos alguns problemas o lixo recolhido quando não vão para os meios de reciclagem, muitos ficam guardados, para acharem algum destino onde deve ser descartado.

O projeto intervenção no uso do agrotóxico tem como objetivo eliminar o uso do agrotóxico, nas pequenas propriedades da comunidade da Lagoa das Flores, que é responsável pela a maior produção de hortaliças consumida no município, além de promover a saúde coletiva, e ambiental evitando o uso inadequado de agrotóxico nessa comunidade. Também são elaborados curso de agroecologia para os agricultores, e promovendo a conscientização do uso dos equipamentos de uso individual (EPI). Já o projeto brincando na lagoa, visa a comemoração dos dias das crianças, para sensibilizar a população para preservação do meio ambiente, por meio de atividades: como a reciclagem, passeio ciclístico, caminhada ecológica e entre outras atividades desenvolvidas.

\section{CONCLUSÕES/RECOMENDAÇÕES}

Um dos temas que vem repercutindo muito ultimamente, tanto no Brasil, quanto no mundo é o meio ambiente, o cuidado que se tem que ter, preocupação em preservar. E para atender a essa preocupação nos municípios foi criado o COMMAM, que é um órgão com a finalidade de proteção ambiental, qualidade ambiental que possam criar mecanismos para aumentar a conscientização da população e para promover o bemestar populacional, viabilizando o desenvolvimento de projetos para o melhoramento do município. A política do meio ambiente de Vitoria da Conquista é tratada pelo 


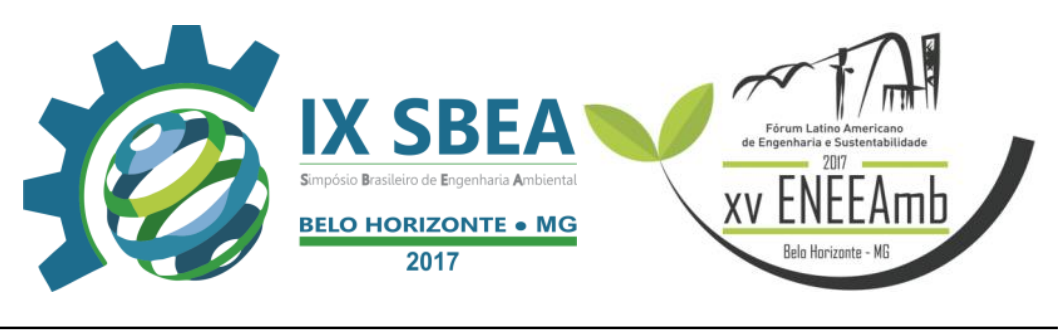

COMMAM, onde serão estabelecidas normas e diretrizes, para a proteção ambiental, proporcionando estratégias para o desenvolvimento sustentável. O COMMAM desenvolve projetos para a melhoria do município todos os anos. Em Vitória da Conquista não foram realizados muitos projetos no ano de 2012 devido ao período eleitoral, alguns projetos que começaram ano passado ainda estão em execução, como exemplo da Cidade verde, restauração das praças, projetos de diagnóstico e monitoramento socioambiental do Parque Lagoa das Bateias, Projeto Floresta Urbana, Adote uma praça. Além de programações realizadas, principalmente na semana de Meio Ambiente, como a Eletro-troca. São projetos que visam realmente a proteção ambiental, tanto por investimentos diretos nas áreas quanto por meio da conscientização da população, projetos bem desenvolvidos, mas se não haver essa conscientização e a participação, que é tão visada pelos órgãos responsáveis, da população não há como resolver sem a participação da população, mas ativa nas questões ambientais e incentivo dos órgãos públicos, principalmente da prefeitura, destinando verba de modo coerente para a realização dos projetos , o conselho acaba perdendo sua função.

\section{REFERÊNCIAS BIBLIOGRÁFICAS}

Brasil é o quinto lugar na lista dos maiores produtores de spam. Cassio W. Barbosa. Acesso em 28 fev. 2013. Disponível em: http://www.tecmundo.com.br/email/34431-brasil-e-o-quinto-lugar-na-lista-dos-maioresprodutores-de-spam.htm.

CARNEIRO, A. G. CRIMES VIRTUAIS: ELEMENTOS PARA UMA REFLEXÃO SOBRE O PROBLEMA NA TIPIFICAÇÃO. ACESSO EM 28 FEV. 2013. DISPONÍVEL EM: JURIDICO.COM.BR/SITE/INDEX.PHP?N_LINK=REVISTA_ARTIGOS_LEITURA $\underline{\text { \&ARTIGO_ID=11529. }}$

Centro de Estudos, Resposta e Tratamento de Incidentes de Segurança no Brasil, CERT.BR. Cartilha de Segurança para a internet. Acesso em 28 fev. 2013. Disponível em: http://cartilha.cert.br/spam/. 


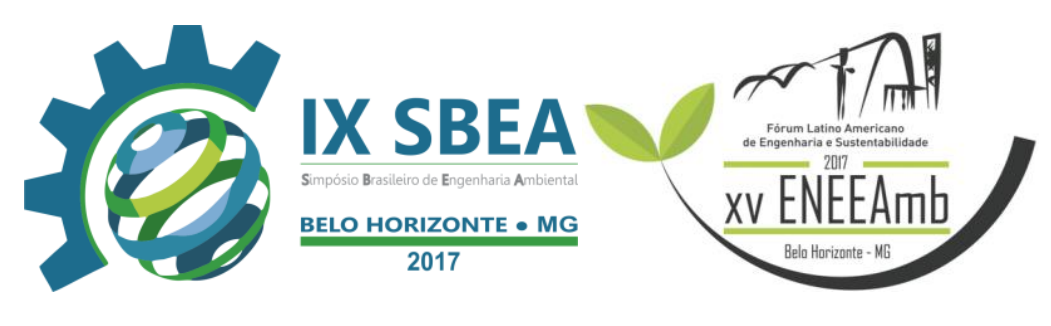

COLlAviZZA, A. W., MENEGAT, F. L., ENNES, M. I. A. Spam. Acesso em 28 fev. 2013. Disponível em: http://www.gta.ufrj.br/grad/09_1/versaofinal/spam/cap3.html.

Conselho Municipal de Meio Ambiente na formulação de políticas públicas. Secretaria Municipal do Verde e do Meio Ambiente. Acesso em 01 de mar. 2014. Disponível em: http://www.bvsde.paho.org/bvsaidis/saneab/peru/bramam174.pdf.

RODRIGUES, G. O que diz a lei brasileira sobre o spam. Acesso em 28 fev. 2013. Disponível em: http://informatica.terra.com.br/virusecia/spam/interna/0,,OI195624-EI2403,00.html.

SILVA NETO, A. M., O Spam e o direito brasileiro. Acesso em 28 fev. 2013. Disponível em: http://www.cjf.jus.br/revista/numero19/artigo6.pdf.

THE CAN-SPAM ACT OF 2003. ACESSO EM 28 FEV. 2013. DISPONÍVEL EM:HTTP://WWW.SPAMLAWS.COM/FEDERAL/INDEX.SHTML.

VIANA, C. S. M. SPAM: UMA ABORDAGEM CRÍTICA. ACESSO EM 28 FEV. 2013. DISPONÍVEL EM: HTTP://JUS.COM.BR/REVISTA/TEXTO/3283/SPAM-UMA-ABORDAGEMCRITICA\#IXZZ2MPACMTJD. 